\title{
The Future of Antibiotic: From the Magic Bullet to the Smart Bullet
}

\section{Stella Cascioferro and Domenico Schillaci*}

Department of Biological, Chemical and Pharmaceutical Science and Technology (STEBICEF), Università degli Studi di Palermo, Italy

\section{Editorial}

The antibiotics have represented a great revolution for humankind, the development after the World War II of a magic bullet (the antibiotic molecule), as imagined by Paul Erlich, the pioneer of chemotherapy, with the property to kill or inhibit the growth of microorganisms by hitting the microbial structures with low toxicity for host cells and tissues, has determined a new era in the treatment and prophylaxisis of infectious disease and in the quality of human life.

However, starting from '50 of last century up to recent decades and currently, a large number of antibiotics, due to the emergence of multidrug-resistant bacterial strains (both Gram-negative and Grampositive), have become scarcely effective and not-useful. It is estimated that drug-resistant strains of bacteria are responsible for 5,000 deaths a year in the UK and 25,000 deaths a year in Europe. The World Health Organization, in the recent (2014) report on antimicrobial resistance in common bacterial pathogens, states that a post-antibiotic era is a close possibility for the $21^{\text {st }}$ century [http://www.who.int/drugresistance/ documents/surveillancereport/en/]. Moreover, there is a lack of investments by pharmaceutical companies in the development of new antibiotics, but new antimicrobials for counteracting the pathogens are needed. This scenario has to stimulate the research of alternative strategies to conventional antibiotics. How could we imagine the antibiotic of future, which additional characteristics should it have? Starting from a good selectivity index (that is the ratio between toxic dose for the host and efficient dose against microbial cells), other important properties to obtain a "smart bullet" will be needed: the ability to hit pathogens without killing beneficial microbiota; a low selectivity pressure to promote the rise in antibiotic-resistance strains; the property to tackle natural form of resistance like multi-stratified microbial population growing on surfaces, the so-called biofilms; the capacity to eliminate "dormant" cells, that is microbial cells metabolically inert and for this naturally resistant to current antibiotics.

The first two objectives could be obtained throw the use of antipathogenic agents. Over the last decade, many studies focused on agents that target the virulence of pathogens without killing or inhibiting the growth of microorganisms and therefore with limited selective pressure to promote the antibiotic resistance development $[1,2]$. A fundamental step of Gram-positive and Gram-negative pathogenesis is the bacterial adhesion to the host tissue involving a direct and a specific interaction between bacterial surface molecules and host ligands. Interfere with adhesion, the first step of pathogenesis, could be an efficient way to prevent or treat infections. The adhesion is a fundamental step for microbial colonization and infection and through it the pathogens also avoid to be mechanically removed from the host [3].

Gram-positive and Gram-negative pathogens adhere to the host tissues through filamentous organelles known as pili $[4,5]$. The pili function on initial bacterial attachment, invasion and biofilm formation, has been mainly studied for Gram-negative bacteria [5]. Some new agents, known as pilicides, have been synthesized to target the chaperone-subunit interaction [6] and the chaperone interaction with a protein involved in the biogenesis of the pili in Gram-negative known as fimbrial usher protein [7]. Uropathogenic Escherichia coli (UPEC) is the major aetiological agent of Urinary Tract Infections
(UTIs) and is often studied as model of Gram-negative pathogen for the development of pilicides compounds.

There are many works on the synthesis of pilicides [6,7], in a recent article on this subject, it has been reported the synthesis of $\mathrm{N}$-(4-chlorophenyl)-2-\{5-[4-(pyrrolidine-1-sulfonyl)-phenyl]-[1,3,4] oxadiazol2-yl sulfanyl $\}$-acetamide as inhibitor of the assembly of type 1 pili interfering with the subunit incorporation cycle of the chaperoneusher pathway [8].

Similar structural motifs of pilin components has been found in an important family of Gram-positive surface proteins, the Microbial Surface Components Recognizing Adhesive Matrix Molecules (MSCRAMMs), able to recognize host's extracellular matrix proteins, such as fibrinogen, fibronectin, and collagen [4,9].

If we consider the important part played by MSCRAMMs in the first step of Gram-positive pathogenesis and of biofilm formation, we believe that new anti-virulence agents could be developed by using as a target the enzyme responsible of linking such proteins to cell wall, that is the Sortase A (SrtA), rather than any single surface protein involved in the mechanism of virulence [10]. The SrtA is a membrane-bound cysteine transpeptidase that is responsible, in Gram-positive bacteria, for the covalent anchoring of surface proteins to bacterial cell wall.

SrtA inhibitors can be classified into three groups: natural compounds, peptides and synthetic small molecules. Natural compounds with SrtA inhibitory activity are obtained principally from plants as Fritillaria verticillata [11], Rhus verniciflua [12], Curcuma longa L [13-15], Coptis chinensis [16], Sophora flavescens [17] and from marine invertebrates like the sponges Spongosorites sp [18], Aaptos aaptos [19], Sceptrella sp [20], Coscinoderma sp [21] and like the ascidian Synoicum sp [22,23].

The first peptides described as SrtA inhibitors were the peptidyldiazomethane and peptidyl-chloromethane analogues, $\mathrm{Cbz}$ (benzyloxycarbonyl)-Leu-Pro-Ala-Thr- $\mathrm{CHN}_{2}$ and Cbz-Leu-ProAla-Thr- $\mathrm{CH}_{2} \mathrm{Cl}$ which found to act as time-dependent irreversible inhibitors of recombinant sortase $(\operatorname{Srt} \mathrm{A} \Delta \mathrm{N})$. The inhibitor sequences mimic the substrate recognition motif of the SrtA (-Leu-Pro-XaaThr-Gly-) with the difference that the scissile amide bond between threonine and glycine residues was replaced with a diazoketone or chloromethyl ketone group, groups able to alkylate the Cys 184 of the

*Corresponding author: Domenico Schillaci, Department of Biological, Chemical and Pharmaceutical Science and Technology (STEBICEF), Università degli Studi di Palermo, Via Archirafi 32, Palermo, Italy, Tel: +3909123891914; E-mail: domenico.schillaci@unipa.it

Received August 06, 2014; Accepted August 07, 2014; Published August 14 2014

Citation: Cascioferro S, Schillaci D (2014) The Future of Antibiotic: From the Magic Bullet to the Smart Bullet. J Microb Biochem Technol 6: e118. doi:10.4172/19485948.1000e118

Copyright: (c) 2014 Cascioferro S, et al. This is an open-access article distributed under the terms of the Creative Commons Attribution License, which permits unrestricted use, distribution, and reproduction in any medium, provided the original author and source are credited 
Citation: Cascioferro S, Schillaci D (2014) The Future of Antibiotic: From the Magic Bullet to the Smart Bullet. J Microb Biochem Technol 6: e118. doi:10.4172/1948-5948.1000e118

Page 2 of 3

enzyme active site [24]. Peptide acting as irreversible inhibitor of SrtA was obtained by Connolly et al. replacing the scissile Thr-Gly in the substrate recognition motif of SrtA with a vinyl sulfone group $(\mathrm{C}=\mathrm{C}$ $\left.\mathrm{SO}_{2} \mathrm{Ph}\right)[25]$.

Regarding synthetic small molecules the most representative were obtained via High-Throughput Screening by Suree et al. that described new derivatives belonging to the three chemical classes of rhodanines, pyridazinones and pyrazolethiones with SrtA IC50 values, for the most active molecules, of $3.7 \mu \mathrm{M}, 0.20 \mu \mathrm{M}$ and $0.30 \mu \mathrm{M}$, respectively. These molecules probably act on the enzyme through a thiol-disulfide exchange reaction with Cys 184 [26].

Other cell surface molecules in Gram-positive bacteria, involved in the adhesion process, without cell wall anchorage, are nonproteinaceous adhesins like Wall Teichoic (WTA) and lipoteichoic acids. Since WTAs are required for host infection and play important role in biofilm formation, it has been suggested that they are important virulence factors required for the estabilishment and spread of infection in a host. Therefore, the enzymes involved in WTAs biosynthesis can be considered as good targets for novel antimicrobials that interfere with Gram-positive pathogenic process. One possible target is the WTA biosynthetic pathway because strains of $S$. aureus and B. subtilis mutants in WTAs are not able to colonize the host tissue and show a greatly diminished ability to establish infection in animal models $[27,28]$.

Current antibiotics can be efficacious against planktonic (free living) pathogens but are poorly effective against bacteria growing as biofilms. Biofilms structured bacteria develop multifactorial mechanisms of antibiotic-resistance and one of the most important factor of tolerance is the slow growth and low metabolic activity of bacterial cells (dormant cells) in the internal layer of community, so they are intrinsically resistant to current antibiotics, which target dividing and metabolically active cells, and represent a reservoir for recurrent infections. The Antimicrobial Peptides (AMPs) [29] generally defined as cationic, amphipathic peptides, with no more than 50 amino acids, are very promising agents in the struggle against pathogenic biofilms, in fact they permeabilize and form pores within the cytoplasmatic membranes, so they can act on slow-growing or even non growing bacteria that exhibited a reduced susceptibility to many antibiotics. The AMPs also have a high potential for interfering with biofilm formation, in fact they could minimize initial adhesion of microbial cells to abiotic surfaces (medical devices etc.) by altering the adhesive features, or by inhibiting quorum-sensing, that is the communication system used by many pathogens to control collective behaviours, such as virulence factors production and biofilm formation.

There are many gaps of knowledge in the research of anti-virulence drugs, for example, the lack of assessment of the efficacy of most SrtA inhibitors by using in vitro or in vivo models of infections. Attenuation of virulence as antimicrobial strategy needs a good host immune defence for bacterial clearance, so immune-compromised patients could not be treated. That is a point of weakness of anti-virulence approach and further studies to improve the pharmaceutical potential of anti-virulence agents are needed. The possibility of using novel antivirulence agents in combination with AMPs that have also immune modulatory functions [30], could contribute to overcoming the above mentioned point of weakness, and make this strategy effective to combat the developing risk of pathogens that current antibiotics cannot defeat.

\section{References}

1. Rasko DA, Sperandio V (2010) Anti-virulence strategies to combat bacteriamediated disease. Nat Rev Drug Discov 9: 117-128.

2. Maresso AW, Schneewind $O$ (2008) Sortase as a target of anti-infective therapy. Pharmacol Rev 60: 128-141.

3. Breines DM, Burnham JC (1994) Modulation of Escherichia coli type 1 fimbrial expression and adherence to uroepithelial cells following exposure of logarithmic phase cells to quinolones at subinhibitory concentrations. J Antimicrob Chemother 34: 205-221.

4. Piatek R, Zalewska-Piatek B, Dzierzbicka K, Makowiec S, Pilipczuk J, et al. (2013) Pilicides inhibit the FGL chaperone/usher assisted biogenesis of the Dr fimbrial polyadhesin from uropathogenic Escherichia coli. BMC Microbiol 13: 131.

5. Cegelski L, Pinkner JS, Hammer ND, Cusumano CK, Hung CS, et al. (2009) Small-molecule inhibitors target Escherichia coli amyloid biogenesis and biofilm formation. Nat Chem Biol 5: 913-919.

6. Svensson A, Larsson A, Emtenäs $H$, Hedenström M, Fex T, et al. (2001) Design and evaluation of pilicides: potential novel antibacterial agents directed against uropathogenic Escherichia coli. Chembiochem 2: 915-918.

7. Pinkner JS, Remaut H, Buelens F, Miller E, Aberg V, et al. (2006) Rationally designed small compounds inhibit pilus biogenesis in uropathogenic bacteria. Proc Natl Acad Sci U S A 103: 17897-17902.

8. Lo AW, Van de Water K, Gane PJ, Chan AW, Steadman D, et al. (2014) Suppression of type 1 pilus assembly in uropathogenic Escherichia coli by chemical inhibition of subunit polymerization. J Antimicrob Chemother 69: 1017-1026.

9. Vengadesan K, Narayana SV (2011) Structural biology of Gram-positive bacterial adhesins. Protein Sci 20: 759-772.

10. Chen L, Wen YM (2011) The role of bacterial biofilm in persistent infections and control strategies. Int J Oral Sci 3: 66-73.

11. Kim SH, Shin DS, Oh MN, Chung SC, Lee JS, et al. (2003) Inhibition of sortase a bacterial surface protein anchoring transpeptidase, by beta-sitosterol-3-Oglucopyranoside from Fritillaria verticillata. Biosci Biotechnol Biochem 67 2477-2479.

12. Kang SS, Kim JG, Lee TH, Oh KB (2006) Flavonols inhibit sortases and sortase-mediated Staphylococcus aureus clumping to fibrinogen. Biol Pharm Bull 29: 1751-1755.

13. Park BS, Kim JG, Kim MR, Lee SE, Takeoka GR, et al. (2005) Curcuma longa L. constituents inhibit sortase $A$ and Staphylococcus aureus cell adhesion to fibronectin. J Agric Food Chem 53: 9005-9009.

14. Hu P, Huang P, Chen WM (2013) Curcumin inhibits the Sortase A activity of the Streptococcus mutans UA159. Appl Biochem Biotechnol 171: 396-402.

15. Hu P, Huang P, Chen MW (2013) Curcumin reduces Streptococcus mutans biofilm formation by inhibiting sortase A activity. Arch Oral Biol 58: 1343-1348.

16. Kim SH, Shin DS, Oh MN, Chung SC, Lee JS, et al. (2004) Inhibition of the bacterial surface protein anchoring transpeptidase sortase by isoquinoline alkaloids. Biosci Biotechnol Biochem 68: 421-424.

17. Oh I, Yang WY, Chung SC, Kim TY, Oh KB, et al. (2011) In vitro sortase A inhibitory and antimicrobial activity of flavonoids isolated from the roots of Sophora flavescens. Arch Pharm Res 34: 217-222.

18. Oh KB, Mar W, Kim S, Kim JY, Oh MN, et al. (2005) Bis(indole) alkaloids as sortase A inhibitors from the sponge Spongosorites sp. Bioorg Med Chem Lett 15: 4927-4931.

19. Jang KH, Chung SC, Shin J, Lee SH, Kim TI, et al. (2007) Aaptamines as sortase A inhibitors from the tropical sponge Aaptos aaptos. Bioorg Med Chem Lett 17: 5366-5369.

20. Jeon JE, Na Z, Jung M, Lee HS, Sim CJ, et al. (2010) Discorhabdins from the Korean marine sponge Sceptrella sp. J Nat Prod 73: 258-262.

21. Bae J, Jeon JE, Lee YJ, Lee HS, Sim CJ, et al. (2011) Sesterterpenes from the tropical sponge Coscinoderma sp. J Nat Prod 74: 1805-1811.

22. Won TH, Jeon JE, Kim SH, Lee SH, Rho BJ, et al. (2012) Brominated aromatic furanones and related esters from the ascidian Synoicum sp. J Nat Prod 75 2055-2061. 
Citation: Cascioferro S, Schillaci D (2014) The Future of Antibiotic: From the Magic Bullet to the Smart Bullet. J Microb Biochem Technol 6: e118. doi:10.4172/1948-5948.1000e118

Page 3 of 3

23. Won $\mathrm{TH}$, Jeon JE, Lee $\mathrm{SH}$, Rho BJ, Oh KB, et al. (2012) Beta-carboline alkaloids derived from the ascidian Synoicum sp. Bioorg Med Chem 20: 40824087.

24. Scott CJ, McDowell A, Martin SL, Lynas JF, Vandenbroeck K, et al. (2002) Irreversible inhibition of the bacterial cysteine protease-transpeptidase sortase (SrtA) by substrate-derived affinity labels. Biochem J 366: 953-958.

25. Connolly KM, Smith BT, Pilpa R, llangovan U, Jung ME, et al. (2003) Sortase from Staphylococcus aureus does not contain a thiolate-imidazolium ion pair in its active site. J Biol Chem 278: 34061-34065.

26. Suree N, Yi SW, Thieu W, Marohn M, Damoiseaux R, et al. (2009) Discovery and structure-activity relationship analysis of Staphylococcus aureus sortase A inhibitors. Bioorg Med Chem 17: 7174-7185.
27. Swoboda JG, Campbell J, Meredith TC, Walker S (2010) Wall teichoic acid function, biosynthesis, and inhibition. Chembiochem 11: 35-45.

28. Rahman O, Dover LG, Sutcliffe IC (2009) Lipoteichoic acid biosynthesis: two steps forwards, one step sideways? Trends Microbiol 17: 219-225.

29. Marr AK, Gooderham WJ, Hancock RE (2006) Antibacterial peptides for therapeutic use: obstacles and realistic outlook. Curr Opin Pharmacol 6: 468472.

30. Wilmes M, Cammue BP, Sahl HG, Thevissen K (2011) Antibiotic activities of host defense peptides: more to it than lipid bilayer perturbation. Nat Prod Rep 28: $1350-1358$ 